\title{
Pregnancy Profile and Perinatal outcome in Gestational Diabetes Mellitus: A Hospital Based Study'
}

\author{
FN MUSTAFA
}

\begin{abstract}
Summary:
Objective: The objective of the study was to measure the proportion of GDM in antenatal outdoor of a hospital, to find out the mean gestational period at which most delivery occurred in GDM and to assess the perinatal outcome.
\end{abstract}

Study design : It was a prospective analytical study conducted in BSMMU, from March,2010 to February,2011.

Method: 1489 pregnant women, not known to be diabetic previously, were selected by consecutive sampling in first trimester from Obstetrics outdoor, BSMMU. Their FBS and blood glucose $2 \mathrm{hrs}$ after $75 \mathrm{gm}$ oral glucose were recorded. We investigated blood glucose in first, second and third trimester in the same pregnant women for screening GDM.

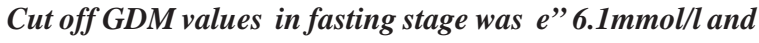

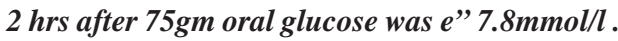

Introduction:

Gestational diabetes mellitus (GDM) is defined as carbohydrate intolerance of varying degrees of severity with onset or first recognition during pregnancy ${ }^{1}$. Diabetes mellitus is the commonest medical complication of pregnancy ${ }^{1}$.

GDM carries significant and often potentially grave fetal and maternal complications. Its early detection and treatment reduces much of the maternal and fetal complications. So, it is very important to diagnose and manage GDM for maternal and fetal wellbeing. The maternal consequences of diabetes in pregnancy are increased incidence of preeclampsia, infection, postpartum bleeding and operative delivery. The consequences to the fetus are more serious than those to the mother. Among the fetal effects, the frequency of congenital abnormalities is increased in women with poorly controlled type I diabetes and the incidence of fetal macrosomia is increased in women with gestational and type II diabetes. There is also increased frequency

Address of Correspondence: Dr Fahmida Naz Mustafa, Junior Consultant (Gynae), Upazilla Health Compex, Daudkandi, Comilla, Tel: 01715038881, 029137145

Received: 12 January, 2014 Accepted: 24 October, 2014
Result: The proportion of GDM in Obstetrics Outdoor of BSMMU was $6.85 \%$. The mean gestational period at which delivery occurred was lower in GDM ( $36.9 \pm 2.2$ wks ) than that in non-GDM (39 \pm 1.6 ws ) .The most common (31.4\%) gestational week during delivery in GDM was 37 completed weeks. Birth weight of $40.2 \%$ babies were in the range of $2.5 \mathrm{~kg}$ to $3.0 \mathrm{~kg}, 31.4 \%$ in the range of 3.1 to $3.5 \mathrm{~kg}$ and $1 \%$ neonate died after birth in GDM.

Conclusion: Presently GDM is diagnosed early. The mean gestational period at delivery in GDM is $36.9 \pm 2.2$ wks. Majority neonatal birth weight is of normal range. Neonatal mortality rate is not increased and is not significantly different from non-GDM women.

Key words: GDM, Gestational week at delivery.

(J Banagladesh Coll Phys Surg 2015; 33: 79-85)

of birth trauma, neonatal metabolic complications, perinatal death etc.

The prevalence of diabetes varies worldwide and among racial and ethnic groups ${ }^{2}$. Prevalence may range from $1-14 \%$ of pregnancy depending upon the population studied and the diagnostic tests employed ${ }^{3}$. These wide ranges of variation in prevalence are due to different diagnostic criteria applied for GDM diagnosis (i.e. ADA, $\mathrm{WHO})^{3,4}$.

There are various recommendations and testing methods to diagnose GDM. In Bangladesh, BIRDEM, BSMMU adopt the diagnostic criteria of WHO (1999) for diagnosing Gestational Diabetes Mellitus. The cut off value of Fasting Venous Glucose Concentration is e"6.1 $\mathrm{mmol} / \mathrm{lit}$, and cut off value of $2 \mathrm{hr}$ post $75 \mathrm{gm}$ oral glucose load is $\geq 7.8 \mathrm{mmol} / \mathrm{lit}^{7}$ for GDM. Important risk factors of Gestational Diabetes Mellitus include higher maternal age, marked obesity (BMI> or equal to $30 \mathrm{~kg} / \mathrm{m}^{2}$ ), personal history of GDM, ethnicity and family history of Type II diabetes in first degree relatives ${ }^{5}$. The prevalence of GDM increases with age, becoming more frequent over the age of 30 years 6,7 .

The above are the important risk factors for GDM. They actually affect blood glucose level by increasing insulin 
resistance. And the most important reason why pregnancy exacerbates the diabetic tendency of asymptomatic women is the progressive increase in insulin resistance that occurs during gestation. During the first and early part of the midtrimester, there is increased sensitivity to insulin and diabetic patients have a tendency towards hypoglycemia. This enhanced insulin sensitivity is probably due to the high levels of estrogen. The opposite occurs in the third trimester when a given dose of insulin has a decreased hypoglycemic effect. The increased insulin resistance stems mainly from the antagonistic effect of human placental lactogen. Accelerated insulin catabolism by renal and placental insulinases and the anti-insulin effects of other hormones (cortisol, estriol, progesterone) produced in large amounts during pregnancy also contribute to insulin resistance. The increased insulin resistance in the third trimester explains why gestational diabetes is more common after 26 weeks. ${ }^{8}$

Diabetes increases the risk of maternal morbidity, perinatal morbidity and mortality which are many times higher than that of non-diabetic pregnant women. The most significant maternal risk with gestational diabetes is the $35 \%$ to $50 \%$ probability to developing type II diabetes later in life. Older studies indicated a significant increase in the incidence of preeclamsia but recent evidence questions this finding 9 . The incidence of cesarean section is higher in GDM women than in a non-diabetic population. Polyhydramnios occurs frequently in GDM, particularly when the fetus is macrosomic. ${ }^{10}$

\section{Fetal and Neonatal Risks:}

Fetal macrosomia, defined as a birth weight greater than or equal to $4000 \mathrm{~g}$, occurs in 17 - $29 \%$ of pregnancies with gestational diabetes as compared to $10 \%$ in nondiabetic population ${ }^{11}$. The incidence of neonatal hypoglycemia is greater in GDM than in normal pregnancies $^{12}$. In a recent study, neonatal morbidity was assessed by a composite outcome that included stillbirth, neonatal macrosomia / LGA (Large for Gestational Age), neonatal hypoglycemia, erythrocytosis and hyperbilirubinemia. Composite morbidity is present in 59\% of untreated GDM, 18 $\%$ of treated GDM and in $11 \%$ of nondiabetic subjects and the incidence of fetal death was 5.4, 3.6, and 1.8 per 1000 in untreated, treated and nondiabetic mothers, respectively ${ }^{13}$.
In the above context, the present study was undertaken to measure the proportion of gestational diabetes in antenatal outdoor of a hospital and to find out the clinical profiles, pregnancy events and perinatal outcome of the gestational diabetes mellitus.

\section{Materials and methods:}

The objective of the study was to see the proportion of gestational diabetes in antenatal outdoor of a hospital and also to find out the mean gestational period at which most delivery occurred in GDM and to assess the perinatal outcome. It was a prospective analytical study conducted in BSMMU, from March,2010 to February,2011. Sampling procedure was consecutive sampling.

A total number of 1852 pregnant women were enrolled into our study, who attended for antenatal check up in BSMMU in their first trimester from 1 March 2010 to 28 Feb 2011. But finally we could collect full data of 1489 women which we took as our sample size. An informed consent was taken from all women who fulfill inclusion criteria and were interested to participate in this study. There was no age limit. The women in first trimester were enrolled. All relevant data including medical and obstetric history, family history and other risk factors for GDM were recorded in a data form. We requested the women to come next day for investigation of blood sugar level after overnight fasting. Their fasting blood glucose level was recorded, thereafter 75 gm glucose was given to take orally, then 2 hours later blood glucose level was again recorded. We investigated blood glucose level in first, second and third trimester; three times in the same pregnant women for screening GDM. Cut off values of Venous Glucose Concentration for GDM , in Fasting is e” $6.1 \mathrm{mmol} / \mathrm{l}$ and $2 \mathrm{hr}$ after $75 \mathrm{gm}$ glucose is e" $7.8 \mathrm{mmol} / \mathrm{l}$. The women who were found to have Gestational Diabetes Mellitus were considered as cases and those who were found to have normal blood glucose level were considered as control group. Then comparison between the findings of two groups were done. The women were followed up and we kept contact with them till delivery. Many women were delivered in BSMMU, but many were delivered in other hospitals too, but we collected the data from the women later by communicating with them through telephone. Women, whose blood glucose level was not controlled by diet alone, were referred to medicine department 
where insulin was added. The pregnancy events and outcome were assessed. Statistical analysis of all the data was done to evaluate the significance of the findings of the two groups.

\section{Result:}

The proportion of GDM in Obstetrics Outdoor of BSMMU was $6.85 \%$.

Age distribution:

Table-I

\begin{tabular}{lccc}
\multicolumn{4}{c}{ Age distribution between GDM and } \\
non-GDM groups & \\
Age*(years) & \multicolumn{2}{c}{ Group } & p-value \\
\cline { 2 - 3 } & $\begin{array}{c}\text { Case } \\
(\mathrm{n}=102)\end{array}$ & $\begin{array}{c}\text { Control } \\
(\mathrm{n}=1387)\end{array}$ & \\
\hline$<20$ & $0(0.0)$ & $187(13.5)$ & \\
$21-30$ & $71(69.6)$ & $1045(75.3)$ & \\
$>30$ & $31(30.4)$ & $155(11.2)$ & \\
Mean \pm SD & $29.0 \pm 4.2$ & $24.8 \pm 4.1$ & $<0.001$ \\
\hline
\end{tabular}

* Data were analysed using Student's t-Test and were presented as mean $\pm \mathrm{SD}$.

The mean age was significantly higher in the case group than that in the control group $(29.0 \pm 4.2$ years vs. $24.8 \pm$ $4.1, \mathrm{p}<0.001$ ). (Table I). The pregnant women of case group were generally older with $30.4 \%$ being more than 30 years old and none was 20 or $<20$ years; whereas the control group was comparatively young with 13.5\% below 20 years and only $11.2 \%$ > 30 years old.

Detail age distribution of case and control groups

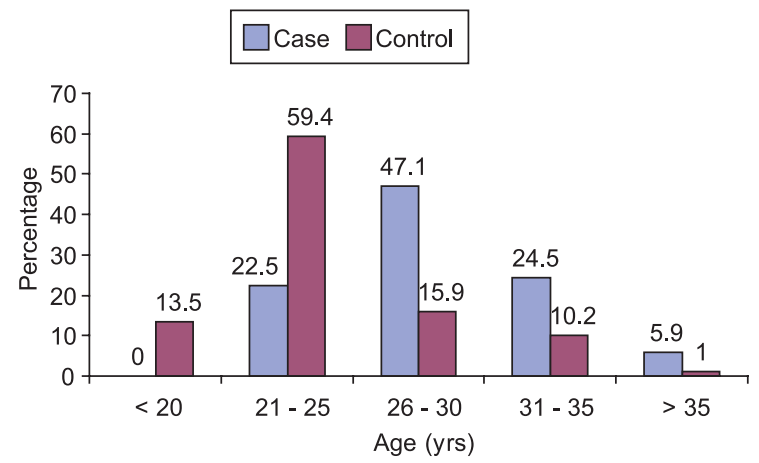

Fig.1: Detail age distribution of case and control groups

In non GDM group the largest age group is $21-25 \mathrm{yrs}$, whereas, in the GDM the largest age group is $26-30$ yrs.
Table-II

\begin{tabular}{lccc}
\multicolumn{4}{c}{$\begin{array}{c}\text { Parity } \\
\text { distribution between cases and } \\
\text { control groups }\end{array}$} \\
Parity & \multicolumn{2}{c}{ Group } & p-value \\
\cline { 2 - 3 } & $\begin{array}{c}\text { Case } \\
(\mathrm{n}=102)\end{array}$ & $\begin{array}{c}\text { Control } \\
(\mathrm{n}=1387)\end{array}$ & \\
\hline Primipara & $22(21.6)$ & $462(33.3)$ & $<0.001$ \\
Multipara & $80(78.4)$ & $925(66.7)$ & \\
\hline
\end{tabular}

Figures in the parentheses indicate corresponding percentage.

* Data were analysed using Chi-square $\left(\div^{2}\right)$ Test

Over three-quarter (78.4\%) of the cases and $66.7 \%$ of the controls were multipara $(\mathrm{p}<0.001)$.

Table-III

\begin{tabular}{lccc}
\multicolumn{4}{c}{$\begin{array}{c}\text { Socio-economic condition of case } \\
\text { and control groups }\end{array}$} \\
\cline { 2 - 3 } Social class & \multicolumn{2}{c}{ Group } & p-value \\
\cline { 2 - 3 } & $\begin{array}{c}\text { Case } \\
(\mathrm{n}=102)\end{array}$ & $\begin{array}{c}\text { Control } \\
(\mathrm{n}=1387)\end{array}$ & \\
\hline Lower class & $6(5.9)$ & $435(31.4)$ & $<0.001$ \\
Middle class & $43(42.2)$ & $447(53.9)$ & \\
Upper class & $53(52.0)$ & $205(14.8)$ & \\
\hline
\end{tabular}

Figures in the parentheses denote corresponding percentage.

* Data were analysed using Chi-square $\left(\div^{2}\right)$ Test.

$52 \%$ of the case group belonged to upper social class and very few to lower class, while about one-third (31.4\%) of the control group belonged to lower social class and only $14.8 \%$ to upper class. The groups were significantly different with respect to social class ( $\mathrm{p}<$ 0.001) (Table III).

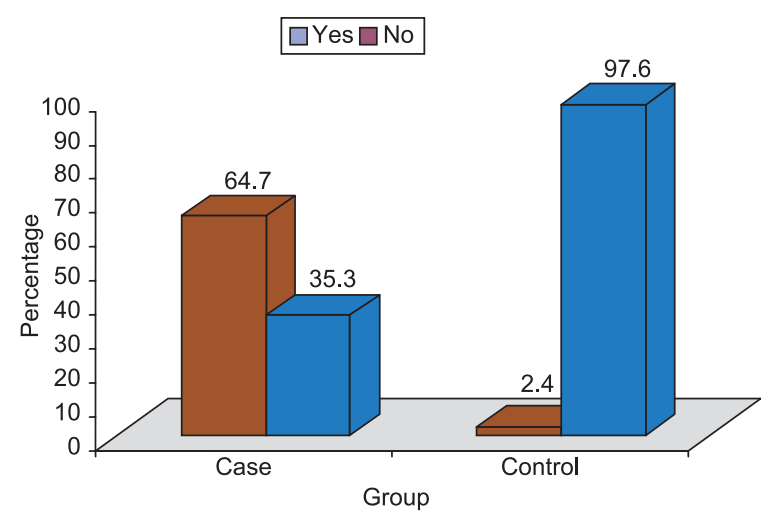

Fig.-2: Distribution of cases and controls by family history of diabetes 
About $64.7 \%$ of the cases had family history of diabetes mellitus as compared to only $2.4 \%$ of the control group $(p<0.001)$ (Fig. 2). The difference is very very significant.

Treatment given:

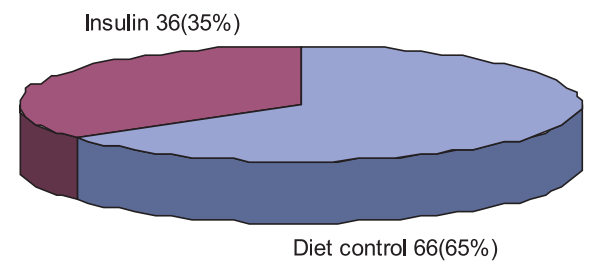

Fig. 3: Distribution of GDM patients by measures taken for diabetes control

About two-third (65\%) of the cases of GDM were controlled by dietary manipulation, while the rest 35\% required insulin.

\section{Table IV}

Gestational period at which delivery occurred

\begin{tabular}{lccc}
$\begin{array}{l}\text { Gestational period } \\
*(\text { weeks) }\end{array}$ & \multicolumn{2}{c}{ Group } & p-value \\
\cline { 2 - 3 } & $\begin{array}{c}\text { Case } \\
(\mathrm{n}=102)\end{array}$ & $\begin{array}{c}\text { Control } \\
(\mathrm{n}=1387)\end{array}$ & \\
\hline$<37$ & $32(31.4)$ & $187(13.5)$ & \\
$37-40$ & $68(66.7)$ & $1145(82.5)$ & \\
$>40$ & $2(1.9)$ & $55(4.0)$ & \\
Mean \pm SD & $36.9 \pm 2.2$ & $39 \pm 1.6$ & $<0.001$ \\
\hline
\end{tabular}

* Data were analysed using Student's t-Test and were presented as mean \pm SD.

Table IV shows that the incidence of preterm delivery (delivery before 37 weeks of gestational period) was much higher in the case group (31.4\%) than that in the control group (13.5\%). The mean gestational period at which delivery of the babies occurred was significantly lower [36.9 \pm 2.2$]$ in the GDM than that in non-GDM $[39 \pm 1.6](\mathrm{p}<0.001)$.

Detail distribution of GDM patients by gestational period at delivery

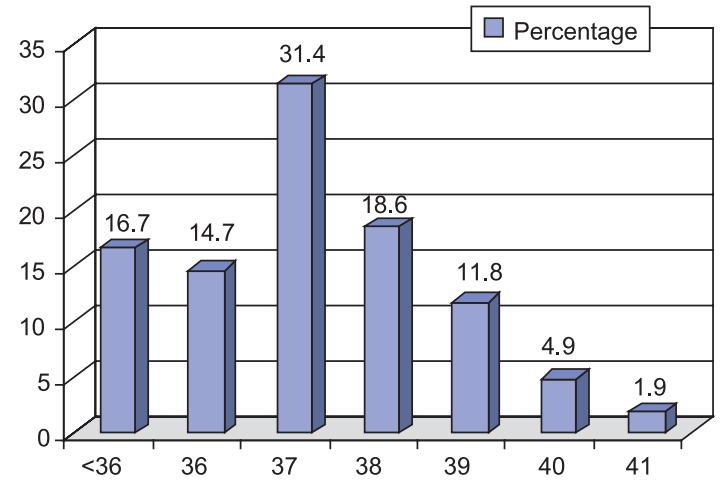

Fig.-4: Detail distribution of GDM patients by gestational period at delivery
The most frequent group of gestational period at delivery in GDM women (31.4\%) is delivery at 37 completed weeks of pregnancy.

Table-V

\begin{tabular}{lccc}
\multicolumn{3}{c}{ Mode of delivery in two groups } \\
Mode of delivery & \multicolumn{2}{c}{ Group } & p-value \\
\cline { 2 - 3 } & Case & Control & \\
& $(\mathrm{n}=102)$ & $(\mathrm{n}=1387)$ & \\
\hline Vaginal delivery & $23(22.5)$ & $747(53.9)$ & $<0.001$ \\
LSCS & $79(77.5)$ & $640(46.1)$ & \\
\hline
\end{tabular}

Figures in the parentheses denote corresponding percentage.

A significantly higher proportion of case group was delivered by caesarean section $(77.5 \%)$ compared to their control counterpart (46.1\%) $(\mathrm{p}<0.001)$.

\section{Table-VI}

\begin{tabular}{|c|c|c|c|}
\hline \multicolumn{4}{|c|}{$\begin{array}{c}\text { Comparison of birth weight of the } \\
\text { babies of two groups }\end{array}$} \\
\hline \multirow[t]{2}{*}{ Birth weight* $(\mathrm{kg})$} & \multicolumn{2}{|c|}{ Group } & p-value \\
\hline & $\begin{array}{c}\text { Case } \\
(\mathrm{n}=102)\end{array}$ & $\begin{array}{c}\text { Control } \\
(\mathrm{n}=1387)\end{array}$ & \\
\hline$\overline{<2.5}$ & 11(10.8) & $126(9.1)$ & 0.001 \\
\hline $2.5-4.0$ & 83(81.4) & 1244(89.7) & \\
\hline$>4$ & $8(7.8)$ & $17(1.2)$ & \\
\hline
\end{tabular}

Figures in the parentheses denote corresponding percentage.

* Data were analysed using Chi-square $\left(\div^{2}\right)$ Test

Large majority of the GDM babies are not macrosomic, $92.2 \%$ of the GDM babies and $98.8 \%$ babies of the nonGDM women are in the non-macrosomic level, $<4.0 \mathrm{~kg}$.

Though the incidence of macrosomia (birth weight of a baby $>4 \mathrm{~kg}$ ) was observed to be significantly higher in

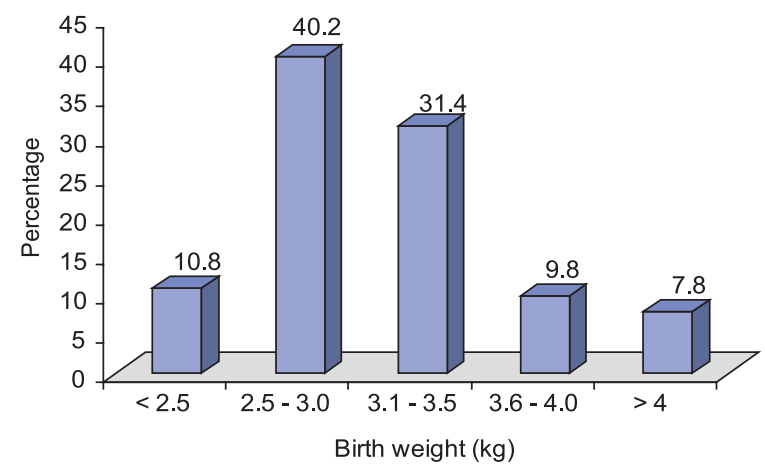

Fig.-5: Detail picture of Birth weight of neonates born of GDM women 
the case group (7.8\%) than that in the control group (1.2\%). ( $p=0.001)$, but the proportion of macrosomia in GDM group itself is not very high (Table VI).

The largest single group of birth weight of neonates ( $40.2 \%$ ) is in the range of $2.5-3.0 \mathrm{~kg}$. The second largest group (31.4\%) is in the range of 3.1 to $3.5 \mathrm{~kg}$. Macrosomic babies are only $7.8 \%$ of the total GDM group babies.

\section{Table-VII}

\begin{tabular}{|c|c|c|c|}
\hline \multicolumn{4}{|c|}{$\begin{array}{c}\text { Comparison of perinatal outcome } \\
\text { between two groups }\end{array}$} \\
\hline \multirow[t]{2}{*}{ Perinatal outcome* } & \multicolumn{2}{|c|}{ Group } & \multirow[t]{2}{*}{ p-value } \\
\hline & $\begin{array}{c}\text { Case } \\
(\mathrm{n}=102)\end{array}$ & $\begin{array}{c}\text { Control } \\
(\mathrm{n}=1387)\end{array}$ & \\
\hline Intrauterine death & $6(5.9)$ & $1(0.1)$ & $<0.001$ \\
\hline Congenital anomaly & $3(2.9)$ & $5(0.4)$ & 0.001 \\
\hline Neonatal death & $1(1.0)$ & $3(0.2)$ & 0.247 \\
\hline
\end{tabular}

Figures in the parentheses denote corresponding percentage.

Table VII shows that $5.9 \%$ of the cases had intrauterine death of the foetus, $2.9 \%$ of the neonates had congenital anomaly and $1 \%$ died after birth. In the control group these figures were $0.1 \%, 0.4 \%$ and $0.2 \%$ respectively. The intrauterine death and congenital anomalies were significantly higher in the case group than those in the control group $(\mathrm{p}<0.001$ and $\mathrm{p}=0.001$ respectively).

\section{Discussion:}

Among 1489 antenatal women studied 102 women were found to have GDM. So the proportion of GDM in obstetrics outdoor of BSMMU was $6.85 \%$. In our country, we have not got any prevalence data of GDM. In a study first published in 2008, the prevalence of GDM in India varied from 3.8 to $21 \%$ in different parts of the country. ${ }^{14}$ In a study, the prevalence of GDM in south India ( Tamil Nadu ) was detected as $17.8 \%$ women in urban, $13.8 \%$ in semi urban and $9.9 \%$ in rural areas. ${ }^{15}$

In a study, conducted in Maharaj Nakorn Chiang Mai Hospital in Thailand in 2001, the prevalence of GDM was found to be $7.05 \%$. In their study , 69\% were multipara, mode of delivery was by vaginal route in 72.4 $\%$ and by LSCS in $27.6 \% .16$

The age range of our study was less than 20 years to more than 40 years. The pregnant women of case group were generally older with $30.4 \%$ being more than 30 years old and none was 20 or $<20$ years; whereas the control group was comparatively younger with $13.5 \%$ below 20 years and only $11.2 \%>30$ years old. The mean age was significantly higher in the former group than that in the latter group $(29.0 \pm 4.2$ years vs. $24.8 \pm 4.1$, $p$ $<0.001)$. Since in 26 - 30 years age range pregnancy is frequent and more women of this group are either $2^{\text {nd }}$ gravida or more. So an evaluation of age distribution reveals that the majority of GDM women were of 26 -30 yrs age range (47.1\%).

A study was run in the Aga Khan Maternity Home, a regional obstetric centre providing maternity care in the northern areas of Karachi. All pregnant women registered for antenatal care and delivery who were not known to be diabetics were included in the study, which ran from January 1990 to December 1992. It was seen that almost one-half were in the range of 25.1-30 years of age 17 (same as in our study, 47.1\% in 26 -30 yrs).

In our study, among GDM women 78.4\% were multipara. In a study, conducted in Maharaj Nakorn Chiang Mai Hospital in Thailand in 2001, 69\% were multipara . ${ }^{16}$

In our study, it is clearly evident that GDM was more frequent in higher socioeconomic status. This finding might be probably due to family history of GDM was more frequent in higher socio economic status for their life style. In the majority of GDM women (64.7\%) family history of Diabetes Mellitus was present, while it was almost absent (only 2.4\%) in non- GDM control group. In a study conducted among GDM women in Kuwait, in 2002, $61.8 \%$ had family history of DM, the finding is almost same as ours. ${ }^{18}$

In our study, majority of women (65\%) had controlled GDM by dietary intervention alone. 35\% women needed insulin. The finding contradicts with the finding in the study conducted among GDM women in Kuwait , in 2002, there 71.1\% GDM women needed insulin therapy and $28.9 \%$ were treated by diet control alone. ${ }^{18}$

A significantly higher proportion of GDM group was delivered with caesarean section (77.5\%) compared to their control counterpart (46.1\%) $(\mathrm{p}<0.001)$. LSCS was done mainly due to patients' complaints of less fetal movement, abdominal pain in previous history of LSCS, higher level of blood glucose level and induction failure. In a study , conducted in Maharaj Nakorn Chiang Mai Hospital in Thailand in 2001, among GDM women, mode 
of delivery was by vaginal route in $72.4 \%$ and by LSCS in $27.6 \%{ }^{16}$ It is in contrast to the findings in our study. Among 394 women delivered at St. Paul's Hospital, University of British Columbia, Vancouver BC., between January 1, 1995, and December 31, 2001, the rate of LSCS was $36.3 \%$ vs. $23 \%$ in control non GDM women $(P<$ 0.05). ${ }^{19}$

The caeserean delivery rate was higher in our study may be because our study was done in 2011 and their study was done in 2001. In this time period, caeserean delivery rate has increased worldwide as a whole. In a study conducted in Virginia, from 2000-2004, caesarean sections increased in mothers with GDM by 84 percent. $^{20}$

The incidence of preterm delivery (delivery before 37 weeks of gestational period) was much higher in the GDM group (31.4\%) than that in non GDM group (13.5\%). The mean gestational period ( $36.9 \pm 2.2 \mathrm{wks}$ ) at which delivery of the babies occurred was significantly lower in GDM than that in non-GDM (39 $\pm 1.6 \mathrm{wks})$.

In our study we have ascertained that the single largest group (31.4\%) of GDM women were delivered at the gestational period of 37 completed weeks. Since women were suffering from GDM and some were treated with Inj Insulin , so they were electively delivered at 37 completed weeks. Many also complained of less fetal movement, they were also delivered at this stage. The second largest group of delivery was at the gestational period of 38 completed weeks. Lesser percentage of women were delivered at 40 weeks (4.9\%). Since they were attending antenatal chek up, so only a few percentage (1.9\%) were delivered at 41 weeks. Since chance of intrauterine death increase in the last few weeks, women had regular antenatal check up and were not allowed beyond EDD. But some women themselves decided to carry the pregnancy further and were delivered at 41 weeks.

In France, in a study in 2001 to 2004, in Reunion Island, there was increased rate of induction of delivery at the gestational period of 38 week. ${ }^{21}$

In our study, birth weight of single majority group of babies (40.2\%) of GDM women were in the range of $2.5 \mathrm{~kg}$ to $3.0 \mathrm{~kg}$. Since a very large group of GDM women delivered at 37 completed weeks and diabetes were under control, so baby weight was in this range. In this study, second largest group $31.4 \%$ babies were in the range of 3.1 to $3.5 \mathrm{~kg}$. Only $17.6 \%$ babies of GDM women weighed $>3.5 \mathrm{~kg}$. Since the women were under regular antenatal check up, blood glucose level was controlled, larger portion of babies were not macrosomic. Though the incidence of macrosomia was observed to be significantly higher in the case group $(7.8 \%)$ than that in the control group (1.2\%).

In a study done in the United States in 1996 on Maternal gestational diabetes and birth weight of babies, it was seen that the mean birth weight was $3.4 \mathrm{~kg}$ for girls and $3.6 \mathrm{~kg}$ for boys. ${ }^{22}$ In another study in the USA macrosomia may affect $20 \%$ of patients with GDM. ${ }^{23}$ In an study in Uganda , macrosomia was found in 36.7\% of GDM women in comparison to $5 \%$ in control group. ${ }^{24}$ In a study in India macrosomia in GDM women were found to be $13 \% .^{25}$

In the study, conducted in The Aga Khan Maternity Home of Karachi, which ran from January 1990 to December 1992, there was an aggregate birth weight of babies of GDM women was $3.24 \mathrm{~kg}$, and perinatal loss was $2.08 \% .{ }^{17}$ In our study, perinatal death occurred to 7 babies out of 102 ( $6.86 \%$ ). Six babies became IUD and one baby died after 2 days of delivery. About $6 \%$ of the GDM cases had intrauterine death of the foetus, $2.9 \%$ of the neonates had congenital anomaly, $1 \%$ neonate died after birth. In the control group, these figures were $0.1 \%, 0.4 \%$ and $0.2 \%$ respectively. The intrauterine death and congenital anomalies were significantly higher in the case group than those in the control group.

\section{Limitations:}

We had some limitations of our study. Initially 1852 women were enrolled into our study, but after dropout we could finally collect the full data of 1489 women. Next limitation was that all the sampled women were not delivered in the same institution they were enrolled first, in BSMMU. We had to collect some data over telephonic conversation with the women in the study.

Another limitation of the study was that a large number of women delivered their babies around 37 completed weeks for various complications, if their pregnancy could continue till EDD, many more babies would have been macrosomic.

\section{Conclusion:}

In our study, $5.9 \%$ of the cases had intrauterine death of the foetus, $2.9 \%$ of the neonates had congenital anomaly and $1 \%$ neonate died after birth. In the control group these figures were $0.1 \%, 0.4 \%$ and $0.2 \%$ respectively. Neonatal mortality rate is not significantly different among GDM \& non-GDM . So, we can conclude that now a days GDM is diagnosed early . In our study, most common gestational period at delivery is 37 completed weeks in GDM, majority neonatal birth 
weight is within normal range and neonatal mortality rate is not increased or significantly different from nonGDM.

\section{Reference:}

1. Stacy L, Strehlow, MD, Jeffrey S et al. Diabetes Mellitus \& Pregnancy. Anne M, Karen Edmonson, Editors. Current Diagnosis and Treatment Obstetrics and Gynaecology. $10^{\text {th }}$ edition. New York :McGrew- Hill publisher ; 2007. page : 311 .

2. Centers for Disease Control. Prenatal care and pregnancies complicated by diabetes. US reporting areas, 1989. MMWR CDC Surveill Summ 1993; 42: 119-22.

3. American Diabetes Association : Clinical Practice Recommendations 2003. Position Statement: Gestational Diabetes Mellitus . Diabetes Care 2003 ; 26 (Suppl. 1): S $103-105$.

4. Definition, diagnosis and classification of diabetes mellitus and its complications. Report of a WHO consultation, Part 1: Diagnosis and classification of diabetes mellitus, Geneva. 1999. page 59, WHO/NCD/NCS/99.2.

5. CG Solomon, WC Willet et al : A prospective study of pregravid determinants of gestational diabetes mellitus. JAMA 1997. 278: 1078-1083.

6. SL Dooley, BE Metzger, NH Cho: Gestational diabetes mellitus : influence of race on disease prevalence and perinatal outcome in a US population. Diabetes 1991. 40: 25-29.

7. DR Coustan, C Nelson, MW Carpenter et al : Maternal age and screening for gestational diabetes: a population based study. Obstet Gynaecol 1989. 73:557-561.

8. Fernando Arias. Diabetes and Pregnancy. Shirish N Daftary, Amaranth G Bhide, Editors. Practical Guide to High Risk Pregnancy And Delivery. 3rd edition. New Delhi: published by Elsevier; 2008. page :440-1.

9. Naylor CD, Sermer $\mathrm{M}$ et al : Caeserean delivery in relation to birth weight and gestational glucose tolerance : pathophysiology or practice style? Toronto Trihospital Gestational Diabetes Investigators. J AM Med Assoc 1996; 275: $1165-70$.

10. Fernando Arias. Diabetes and Pregnancy. Shirish N Daftary, Amaranth G Bhide, Editors. Practical Guide to High Risk Pregnancy And Delivery. 3rd edition. New Delhi: published by Elsevier; 2008 . page :445 .

11. Adams KL, Hongshe L, et al : Sequele of unrecognized gestational diabetes. Am J Obstet Gynaecol 1998 ; 178:1321 -32.
12. Garner P, Okun N, Keely E, et al. A randomized control trial tertiary level obstetric care versus routine care in the management of gestational diabetes. Am J Obstet Gynaecol1997; 177: 190 - 95.

13. Langer $\mathrm{O}$, Yogev $\mathrm{Y}$ et al . Gestational diabetes : the consequences of not treating . Am J Obstet Gynaecol 2005; 192: 989 - 97 .

14. V Seshiah, Sahay BK et al. GESTATIONAL DIABETES MELLITUS - Indian Guidelines. Associated Medical Fraternity : Diabetes in pregnancy Study Group India (DIPSI). Page 2.

15. Seshiah V, Journal of Association of Physicians of India, 2008, vol. 56, pp. 329-333.

16. Pharuhas Chanprapaph , Chatdao Sutjarit. J Med Assoc Thai Vol. 87 : No.10. 2004.pages 1141-6 .

17. Fatema Jawad, Eastern Mediterrane Health Journal, vol 2, issue 2, 1996. page 268 - 273.

18. Fatma AAl-Sultan1, Clinical Epidemiology of Gestational Diabetes in Kuwait, Kuwait Medical Journal 2004 , 36 (3) :195 - 198. .

19. Kevin Johns, J Obste Gynaecol Can 2006;28(2): Pages $122-127$.

20. CDC National Fact Sheet, 2007,.virginia health information , inc., Hospital discharge Database. This article is available from : www.cdc.gov/diabetes/pubs/ estimates.htm

21. Vivet Lifeboure A, Roman $\mathrm{H}$, et al. Clinique gynaecologique et obstetricale, centre Hospitalier Universitair de Rouen, France. Gynecol Obstet Fertil. 2007 Jun;35(6):530-5.

22. Gillman MW, Rifas-Shiman S, et al. Maternal gestational diabetes, birth weight, and adolescent obesity. Pubmed. US National Library of Medicine . Pediatrics. 2003 Mar;111(3):e221-6.

23. Kelly L, Evans L, Messenger D. Controversies around gestational diabetes. Practical information for family doctors. Can Fam Physician 2005; 51: 688-95

24. Emmanuel Odar, Julius andabwa, Paul Kiondo. Maternal and fetal outcome of gestational diabetes mellitus in Mulago Hospital, Uganda. Afr Health Sciences. 2004 April; 4(1): 9-14.

25. Papa Dasari, Syed Habeebullah. Maternal and Fetal Outcome in Gestational Diabetes Mellitus (GDM) Treated with Diet and Metformin - A Preliminary Retrospective Analysis. The Open Conference Proceedings Journal, 2011, 2, 59-63. 